\title{
ANALISIS KONEKTIVITAS DAN KARAKTERISASI PELORONGAN DENGAN UJI PERUNUTAN PADA MATAAIR EPIKARST SUB-SISTEM PANGGANG, KAWASAN KARST GUNUNGSEWU
}

\author{
Indra Agus Riyanto ${ }^{1}$, Ahmad Cahyadi ${ }^{1,}$, Tjahyo Nugroho Adji ${ }^{1}$, Eko Haryono ${ }^{1}$, \\ M. Widyastuti ${ }^{1}$, Romza Fauzan Agniy ${ }^{1}$, Wilda Aulia Fathoni ${ }^{1}$, Novita Rahmawati ${ }^{1}$ \\ dan Haryo Baskoro ${ }^{1}$ \\ ${ }^{1}$ Kelompok Studi Karst, Fakultas Geografi, Universitas Gadjah Mada, Yogyakarta \\ Email: ahmadcahyadi@geo.ugm.ac.id, adji@geo.ugm.ac.id
}

\begin{abstract}
ABSTRAK. Sub-sistem hidrogeologi Panggang merupakan salah satu sub-sistem di Kawasan Karst Gunungsewu yang terletak di paling barat. Karakter mataair yang berkembang di sub-sistem ini adalah mataair epikarst dengan debit yang tidak terlalu besar. Penelitian ini bertujuan untuk menganalisis konektivitas antara sungai bawah tanah Kalinangka dan Mataair Guntur yang terletak di Desa Girijati, Kecamatan Purwosari, Kabupaten Gunungkidul. Sistem ini merupakan bagian dari Sub-sistem Hidrogeologi Panggang, Kawasan Karst Gunungkidul. Analisis konektivitas dilakukan dengan uji perunutan dengan larutan tinopal dan fluorometer. Injeksi tinopal dilakukan di Sungai Bawah Tanah Kalinangka, sedangkan fluorometer sebagai pencatat diletakkan di Mataair Guntur. Hasil yang diperoleh terdapat konektivitas antara mata air Guntur dengan Sungai Bawah Tanah (SBT) Kali Nangka yang berjarak 1,3 km dengan durasi perjalanan 5 jam setelah penuangan larutran tinopal. Karakterisasi pelorongan berdasarkan pada breaktrought curve menunjukkan lorong yang berupa single conduit yang sudah sangat berkembang.
\end{abstract}

Kata kunci: Konektivitas, Karakterisasi Pelorongan, Uji Perunutan, Sub-sistem Panggang, Karst Gunungsewu

\section{PENDAHULUAN (INTRODUCTION)}

Gunungsewu merupakan bagian dari geopark yang memiliki keunikan bentang alam karst baik secara morfologi dan hidrogeologinya (Haryono dan Suratman, 2010). Keunikan hidrogeologi kawasan karst memiliki sistem akuifer berupa porositas sekunder yang terdiri atas diffuse, fisure, dan condouit (Haryono dan Adji, 2004). Sub-sistem Panggang merupakan salat satu sistem hidrogeologi yang berada di kawasan karst gunungsewu (Kusumayudha, 2002). Sistem hidrogeologi Sub-sistem Panggang memiliki karakter yang termasuk dalam kategori SBT yang sumberdaya airnya terbatas (Widyastuti et al., 2018).

Selain itu, kajian di Sub-sistem Panggang cukup minim diteliti terkhusus terkait sungai bawah tanah (SBT) dan hanya berfokus pada kondisi mata air (Adji dan Yoga, 2016; Adji et al., 2016). Kebanyakan SBT banyak diteliti di Sub-sistem Wonosari-Baron yang memiliki debit dan sumberdaya air yang melimpah (Adji, 2010; Adji, 2011; Widyastuti, et al., 2011; Adji, 2012). Oleh karena itu, diperlukan penelitian terkait dengan kondisi SBT yang ada di kawasan Sub-sistem Panggang. Penelitian tersebut penting karena masyarakat di Sub-sistem Panggang menggunakan mata air dan SBT sebagai sumber air utama.

Tujuan penelitian ini adalah untuk mengetahui hubungan dari SBT Nangka (Kali Nangka) dengan Mata Air Guntur. Metode yang digunakan adalah uji perunutan menggunakan larutan tinopal dan dipantau menggunakan flourometer. Penelitian tersebut diharapkan 
dapat menjadi bahan pertimbangan untuk konservasi air dikawasan karst Sub-sistem Panggang dan dapat menunjukkan tingkat perkembangan kawasan karst di sub-sistem ini.

\section{LOKASI PENELITIAN (STUDY AREA),}

Mata Air Guntur dan SBT Kali Nangka terletak di Kecamatan Purwosari, Desa Girijati, Dusun Dringo, Kabupaten Gunungkidul, DI Yogyakarta (Gambar 1). Lokasi kajian terletak pada koordinat $110^{\circ} 21^{\prime} 00^{\prime}$ ' Bujur Timur dan 759'30', Lintang Selatan. Lokasi Kajian termasuk dalam Formasi Wonosari dengan lithologi berupa gamping terumbu dan gamping bioklastik Kala Pliosen (Kusumayudha, 2009). Lokasi kajian memiliki 3 bentuklahan yaitu Crest, Slope, dan Foot Bottom dengan horison tanah yang terdiri atas horison A, $\mathrm{Bw}$, dan C (Haryono et al., 2016). Curah hujan di Kecamatan Playen dari tahun 1954 2009 berkisar $2200-2400 \mathrm{~mm} / \mathrm{tahun}$ (Brunsch, et.al., 2011).

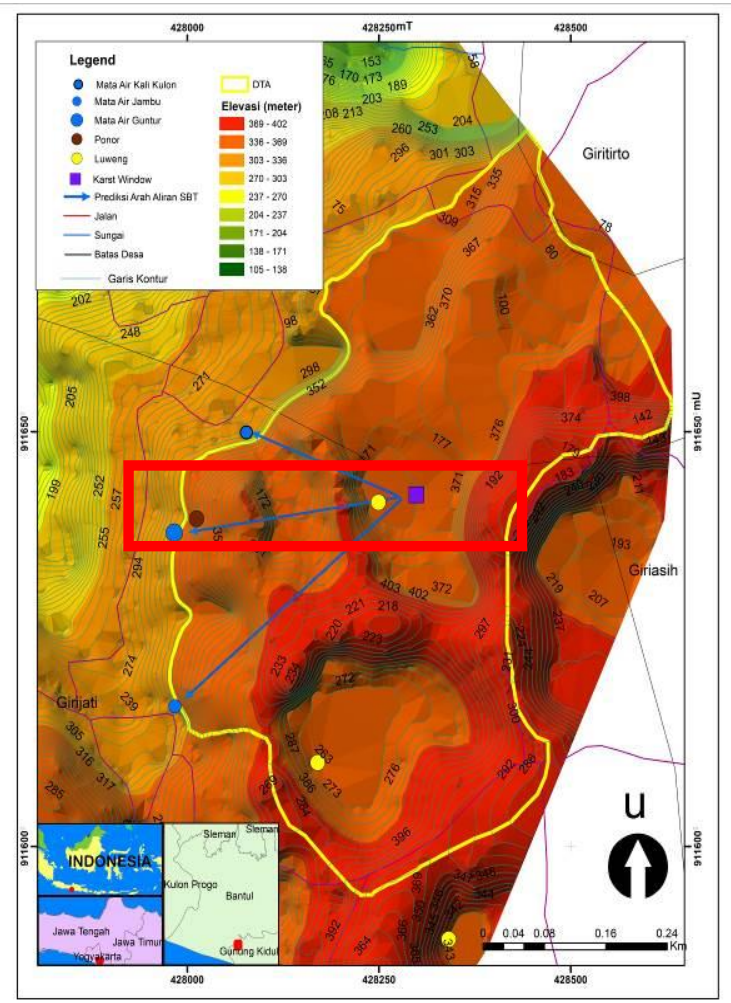

Gambar 1. Lokasi Kajian

\section{METODE (METHODS)}

Metode uji perunutan dilakukan dengan menggunakan larutan tinopal yang termasuk dalam kelompok flourescent dyes dengan karakteristik batasan deteksi larutan $10-^{1} \mu \mathrm{g} / \mathrm{L}$ dan sangat sensitif dengan cahaya (Goldscheider et al., 2008). Larutan tinopal yang digunakan untuk uji perunutan yang dilepas di badan air termasuk bahan yang aman dan tidak memiliki dampak terhadap lingkungan yang dilalui meskipun badan air mengalami perubahan warna (Behrens et al., 2001).

Jumlah larutan tinopal yang digunakan sesuai dengan persamaan rumus hubungan jarak dengan besarnya larutan yang dituangkan (Käss, 1998). Persamaan tersebut dijelaskan sebagai berikut :

$$
\mathbf{M}=\mathbf{L} \cdot \mathbf{k} \cdot \mathbf{B}
$$

$\mathrm{M}=$ jumlah tarcer yang digunakan $(\mathrm{Kg})$

$\mathrm{L}=$ jarak titik injeksi dan pemantauan $(\mathrm{Km})$

$\mathrm{K}=$ koefisien larutan (nilai flourosence selain berkisar uranin 2-15)

$\mathrm{B}=$ faktor kondisi hidrogeologi $(0,1-0,9$ untuk akuifer karst)

Alat yang digunakan dalam uji perunutan terdiri dari Global Positioning System (GPS) untuk penentuan lokasi, flurometer untuk perekaman data konsentrasi larutan Tinopal dilakukan dengan menggunakan (Goldscheider et al., 2008), loger tinggi muka air (water level logger) untuk merekam tinggi muka air sebagai cerminan nilai debit air di lokasi pemantauan, dan weather station untuk merekam data hujan dan data meteorologis lain yang mungkin berpengaruh terhadap hasil penelitian. Bahan yang digunakan berupa larutan tinopal sebagai bahan yang dilepaskan ke badan air. Pemasangan Flourometer dilakukan di Mata Air Guntur (Gambar 2) dan penuangan larutan Tinopal dilakukan di SBT Nangka (Gambar 3).

Flourometer yang digunakan merekam konsentrasi larutan setiap 10 menit dan hasil pencatatannya diolah menggunakan software Fluo (Agniy., dkk., 2017). Analisis dari software Fluo menghasilkan hidrokemograf yang berupa grafik konsentrasi larutan yang di kelaskan sesuai dengan tipe Breakthrough Curve 
Makalah ini dipresentasikan dalam Pekan Ilmiah Tahunan Perhimpunan Ahli Airtanah Indonesia (PAAI) yang diselenggarakan di Hotel Aryaduta, Jakarta, 7 - 8 November 2018

(Cahyadi dan Agniy, 2016). Analisis lebih lanjut uji perunutan diolah menggunakan Microsoft Excel untuk menggabungkan data konsentrasi larutan, data debit, dan curah hujan untuk dianalisis.

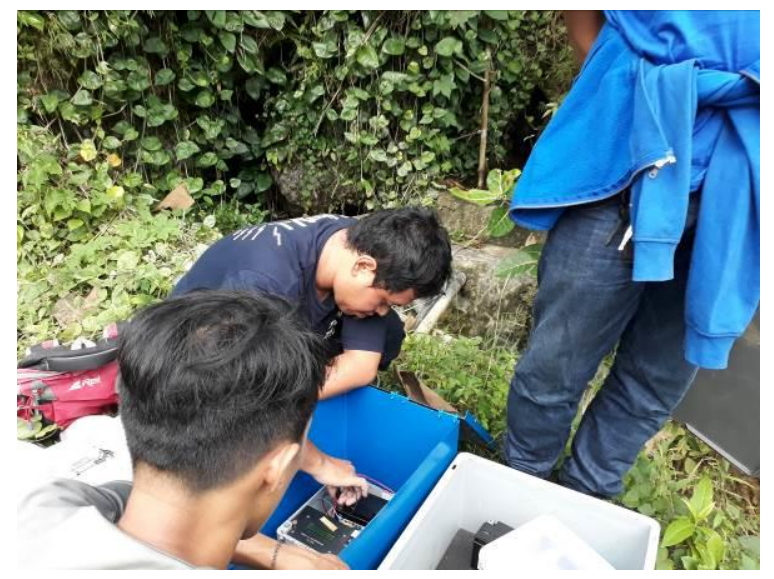

Gambar 2. Pemasangan Flourometer di Mata Air Guntur

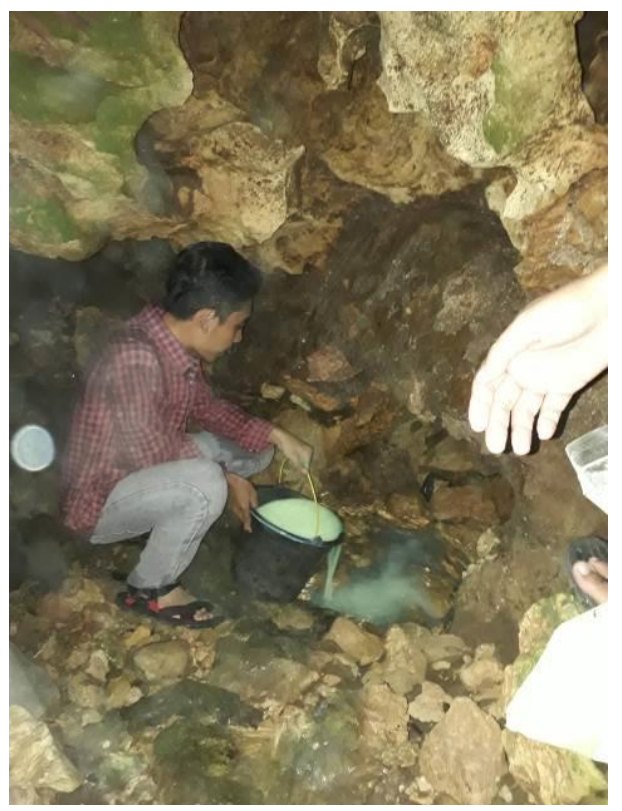

Gambar 3. Penuangan Larutan Tinopal di SBT Nangka

\section{HASIL DAN PEMBAHASAN (RESULT AND DISCUSIONS)}

Uji perunutan dilakukan untuk mengetahui hubungan SBT Nangka (Gambar 4) dengan Mata Air Guntur (Gambar 5).
Sungai Bawah Tanah Nangka diperkirakan merupakan bagian dari Daerah Tangkapan Air (DTA) Mata Air Guntur (Widyastuti et al., 2018). Lokasi SBT Nangka berada di sebelah timur dari Mata Air Guntur (Gambar 1). Karakteristik SBT Nangka mengalir ke arah selatan, sedangkan Mata Air Guntur mengalir ke arah barat. Morfologi SBT Nangka berada pada cekungan dengan elevasi 371 mdpal, sedangkan Mata Air Guntur berada pada morfologi perbukitan dengan elevasi 309 mdpal.

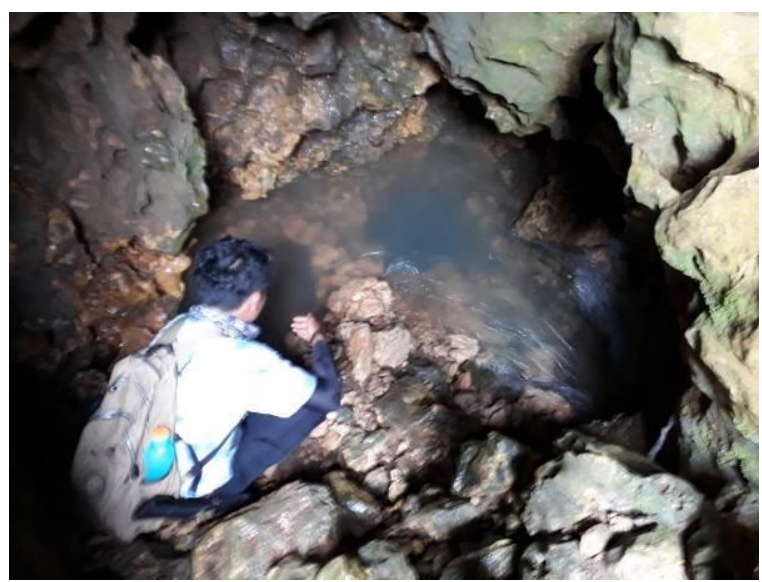

Gambar 4. Sungai Bawah Tanah Nangka

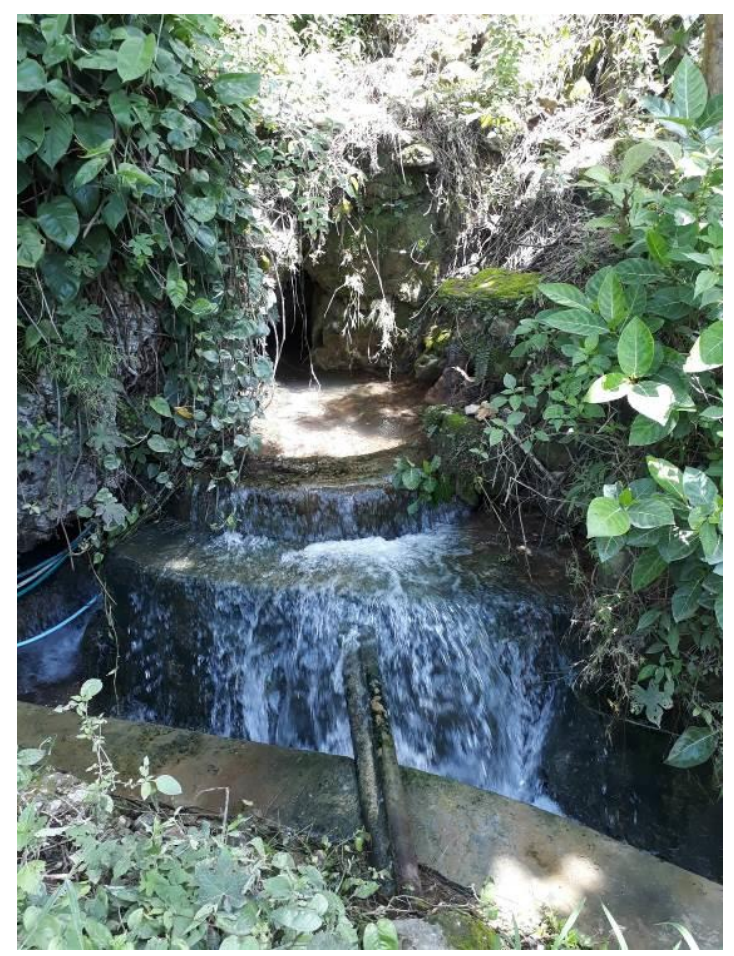

Gambar 5. Mata Air Guntur 
Uji perunutan menggunakan bahan pelacak berupa tinopal yang diinjeksikan di Kali Nangka. Bersamaan dengan itu, telah dipasang alat pendeteksi zat perunut berupa fluorometer di Mata Air Guntur. Jarak datar antara SBT Nangka dan Mata Air Guntur adalah kurang lebih 1,3 $\mathrm{Km}$ dan diperlukan tinopal sebanyak 500 gram. Injeksi dilakukan pada tanggal 20 April 2018 pukul 17.00 WIB di SBT Kali Nangka.

Hasil pembacaan konsentrasi tinopal mulai terdeksi pada pukul 22.00 WIB pada tanggal 20 April 2018 (Gambar 6) dan memiliki konsentrasi tertinggi pada tanggal 21 April 2018 pukul 00.30 WIB. Resesi mulai terjadi pada tanggal 21 April pukul 01.00 WIB hingga melandai dengan konsetrasi 2.425, 81 Part Per Bilion (ppb) dan konsentrasi terendah pada tanggal 23 April 2018 pukul 13.00 WIB sebesar 14,95 ppb. Puncak konsentrasi larutan tinopal kedua terjadi pada tanggal 23 April pukul 17.00 WIB dan memiliki konsentrasi tertinggi pada tanggal 23 April 2018 pukul 17.00 WIB sebesar 556,92 ppb. Penurunan konsentrasi pada puncak kedua mulai terjadi pada tanggal 24 April 2018 pukul 01.00 WIB dan mulai melandai pada konsentrasi normal tanggal 24 April 2018 pukul 11.00 WIB sebesar 15,28 ppb.

Hasil pembacaan grafik hubungan debit, curah hujan, dan konsetrasi Larutan Tinopal diperoleh beberapa hubungan masing-masing parameter. Terdapat hubungan berbanding terbalik antara debit dan konsentrasi larutan. Hubungan tersebut memiliki pola apabila terjadi kenaikan debit maka konsentrasi larutan akan turun dan berlaku sebaliknya. Hubungan hujan dan konsentrasi larutan juga dapat di ketahui berdasarkan keterdapatan hujan pada beberapa hari sebelum pada tanggal 17 April 2018 sebesar $7 \mathrm{~mm}$ sebelum penuangan larutan tinopal membuat menaikan debit air pada SBT sehingga berdampak pada proses kenaikan dan penurunan konsentrasi larutan yang tergolong cepat pada puncak 1. Hal tersebut berbeda pada puncak 2 yang curah hujan sebelumnya hanya sebesar $2 \mathrm{~mm}$ sehingga waktu resesinya lebih lambat dibandingkan puncak 1 .

Hasil analisis berdasarkan kurva hidrokemograf hasil uji perunutan terdapat 1 puncak utama yang menunjukkan lorong yang berupa single conduit yang sudah sangat berkembang (Goldscheider et al., 2008). Puncak ke dua dan ketiga terjadi setelah masa resesi. Puncak tersebut disebabkan karena hujan yang terjadi pada tanggal 22 dan 23 April 2018 yang melarutkan sisa larutan tinopal yang masih tersisa di dalam lorong sungai bawah tanah (Gambar 7).

Keterhubungan antara SBT Nangka dengan Mata Air Guntur memberikan gambaran bahwa keduanya merupakan satu sistem yang saling terkait, sehingga memiliki risiko tercemar cukup tinggi. Karena potensi pencemaran yang cukup tinggi akibat keterhubungan SBT Nangka dengan Mata Air Guntur, maka diperlukan konservasi pada daerah tangkapnnya. Hal ini agar air tetap terjaga kualitas dan kuantitasnya. Keterhubungan keduanya memperkuat penelitian sebelumnya bahwa SBT Nangka termasuk dam DTA Mata Air Guntur (Widyastuti et.al., 2018). 
Makalah ini dipresentasikan dalam Pekan IImiah Tahunan Perhimpunan Ahli Airtanah Indonesia (PAAI) yang diselenggarakan di Hotel Aryaduta, Jakarta, 7 - 8 November 2018

\section{Hidrokemograf}

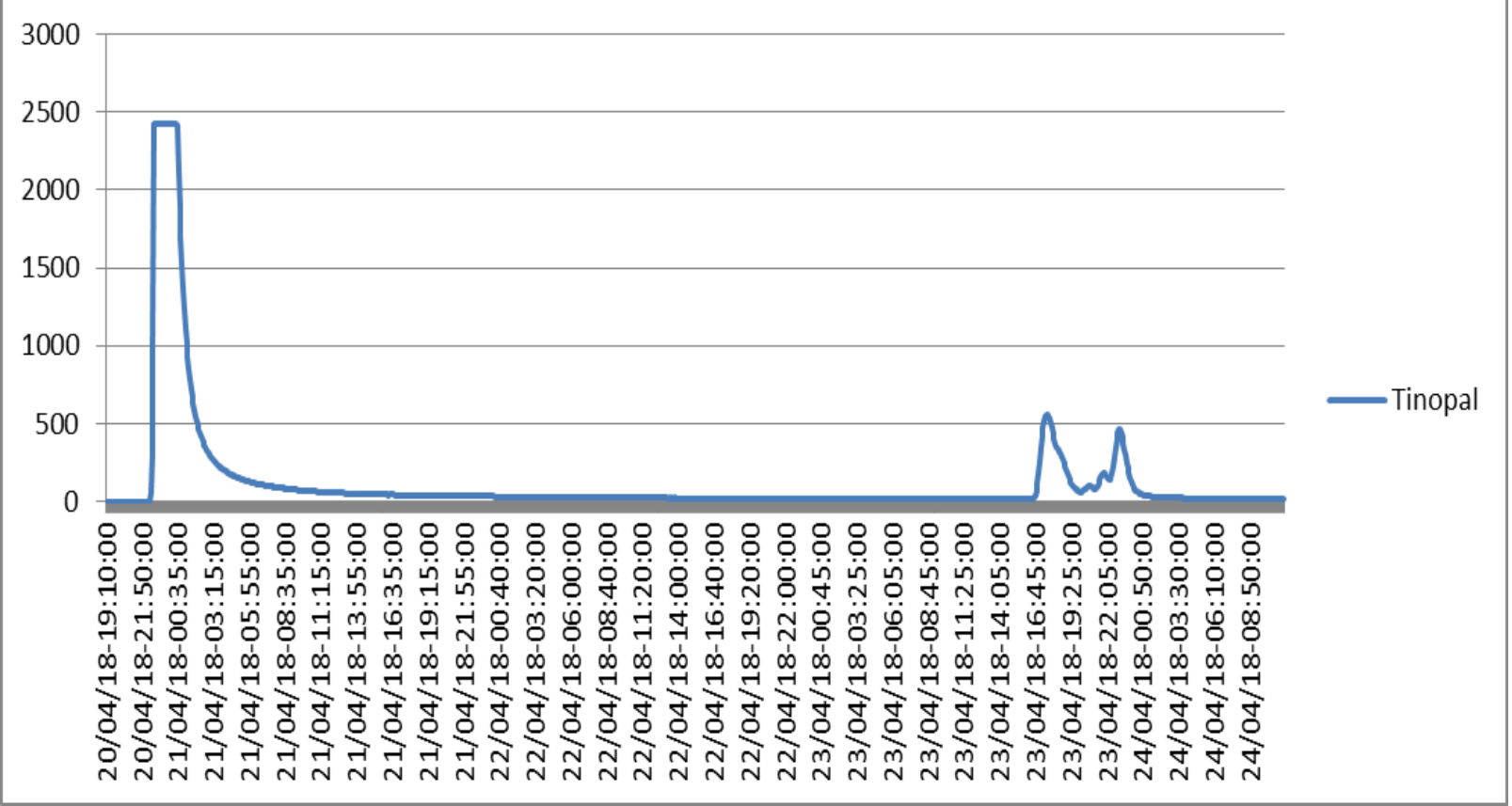

Gambar 6. Hidrokemograf Uji Perunutan (Hasil olah data, 2018)

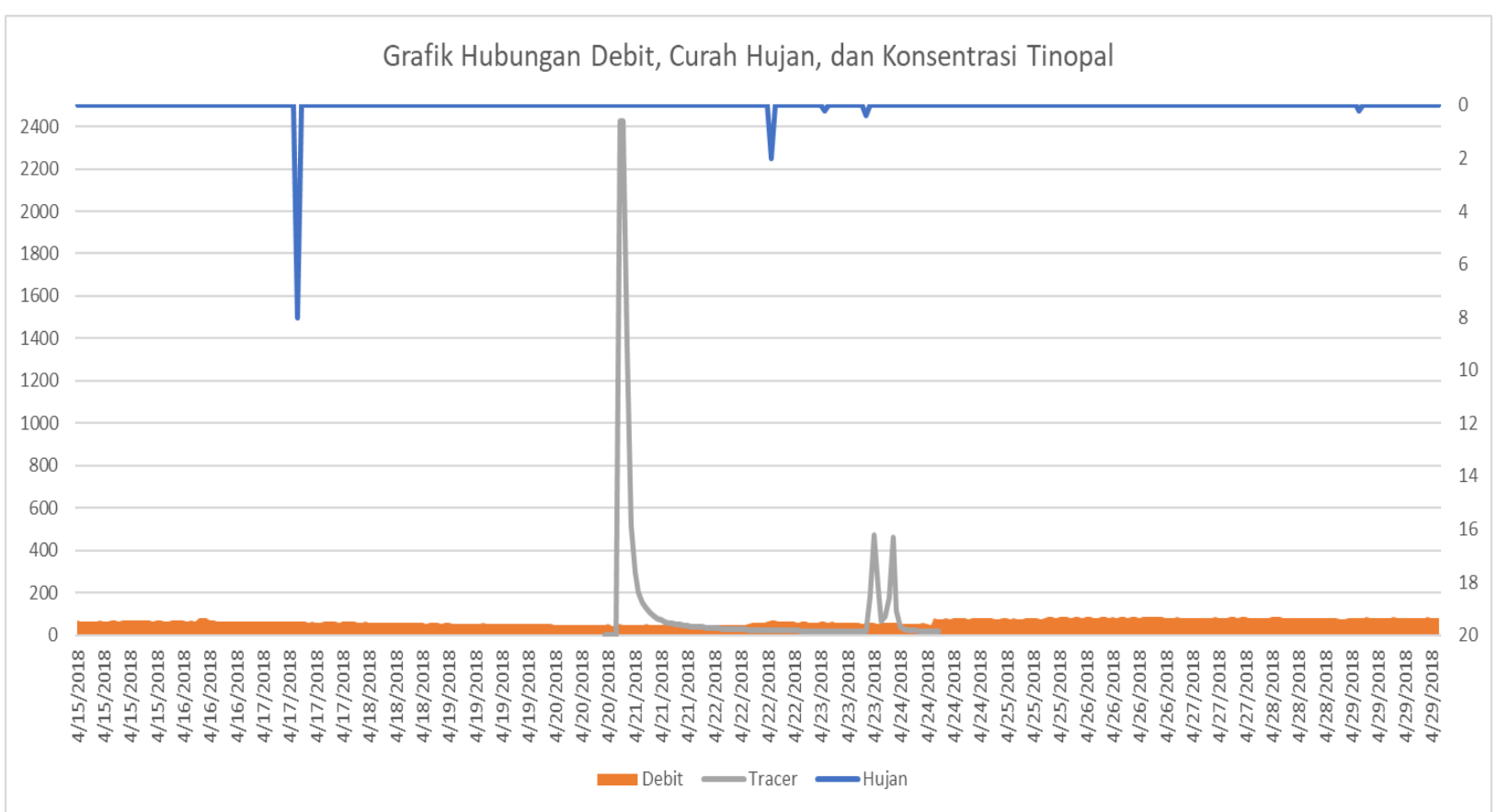

Gambar 7. Grafik Hubungan Konsentrasi Tinopal, Debit, dan Curah Hujan Mata Air Guntur (Hasil Olah., 2018) 


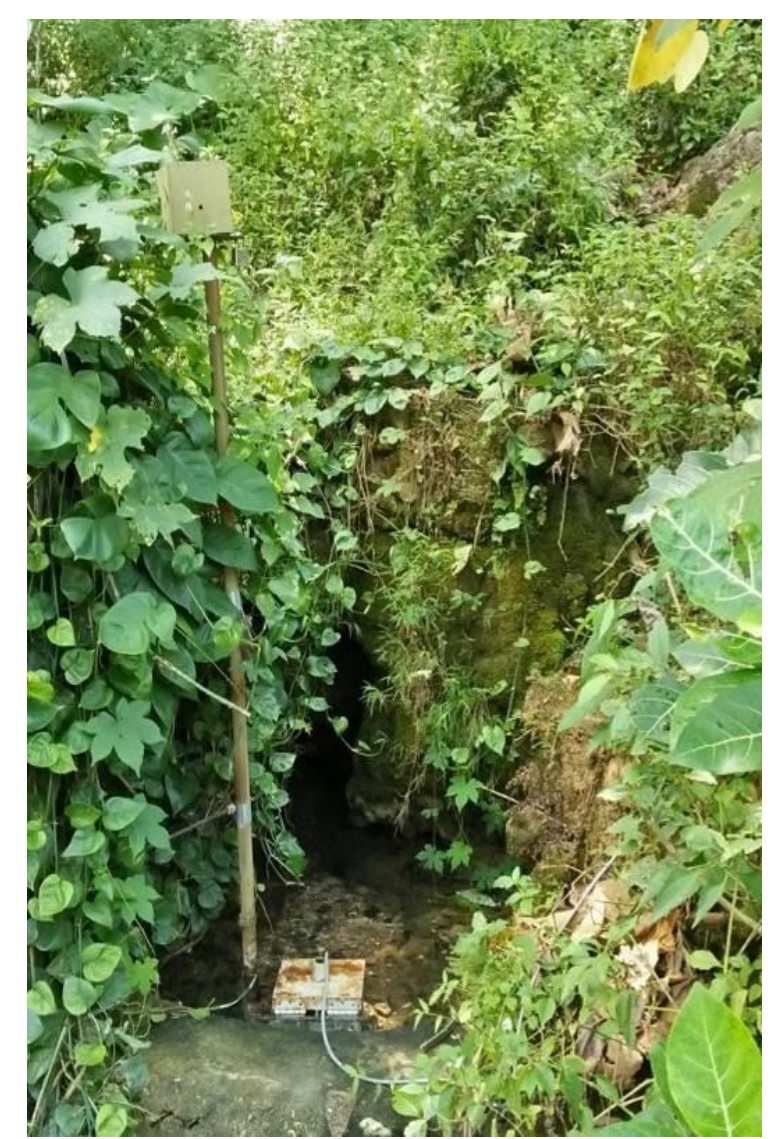

Gambar 8. Loger Debit dan Sensor

Flourometer Pemasangan

\section{KESIMPULAN (CONCLUSION)}

Sungai Bawah Tanah Nangka dan Mata Air Guntur memiliki keterhubungan. Keterhubungan tersebut meningkatkan potensi untuk tercemar, sehingga perlu dilakukan konservasi pada wilayah DTA Mata Air Guntur.

\section{UCAPAN TERIMAKASIH (ACKNOWLEDGEMENT)}

Penelitian ini merupakan bagian dari Thesis di MPPDAS Fakultas Geografi Universitas Gadjah Mada. Penelitian ini dibiayai oleh Kementerian Riset, Teknologi dan Pendidikan Tinggi Republik Indonesia melalui skema Penelitian Dasar Unggulan Perguruan Tinggi (PDUPT) tahun 2018 dengan nomor kontrak 38/UN1/DITLIT/DIT-LIT/LT/2018.

\section{DAFTAR PUSTAKA (REFERENCES)}

Adji, T.N., Haryono, E., Fatchurohman, H., Oktama, R. 2016. Diffuse flow characteristics and their relation to hydrochemistry conditions in the Petoyan Spring, Gunungsewu Karst, Java, Indonesia. Geosci J (2016) 20: 381. https://doi.org/10.1007/s12303015-0048-8.

Adji, T.N.2010. The distribution of flood hydrograph recession constant for Characterization of karst spring and underground river flow Components releasing within gunungsewu karst region. Indonesian Journal of Geography 2010, 12(1), 1- 15.

Adji, T.N.2011. Pemisahan Aliran Dasar Bagian Hulu Sungai Bribin pada Aliran Gua Gilap, di Kars Gunungsewu, Gunung Kidul, Yogyakarta. Jurnal Geologi Indonesia, 6 (3), 165-175.

Adji, T.N.2012.Wet Season Hydrochemistry Of Bribin Cave In Gunungsewu Karst, Indonesia. Environ Earth Sci (2012) 67:1563-1572.

Adji, T.N.2016. Rainfall Discharge Relationship and Karst Flow Component Analysis for Karst Aquifer Characterization in Petoyan Spring, Java, Indonesia. Environ Earth Sci (2016) 75:735

Agniy, R.F., Cahyadi, A., dan Nurkholis, A. 2017. Analisis Karakteristik Akuifer Karst Dengan Uji Perunutan Dan Pemetaan Gua. Proceeding Kongres \& Pertemuan Ilmiah Tahunan ke-2 Perhimpunan Ahli Airtanah Indonesia (PIT-PAAI). Yogyakarta, $13-15$ September 2017.

Behrens, H., Beims, U., Dieter, H., Dietze, G., Eikmann, T., Grummt, T., Hanisch, H., Henseling, H., Käß, W., Kerndorff, H., Leibundgut, C., Müller-Wegener, U., Rönnefahrt, I., Scharenberg, B., Schleyer, R. Schloz, W., and Tilkes F. 2001. Toxicological 
Makalah ini dipresentasikan dalam Pekan Ilmiah Tahunan Perhimpunan Ahli Airtanah Indonesia (PAAI) yang diselenggarakan di Hotel Aryaduta, Jakarta, 7 - 8 November 2018

and ecotoxicological assessment of water tracers. Hydrogeology Journal (2001) 9:321-325

Brunsch, A., Adji, T.N., Stoffe, D., Ikhwan, M., Oberle, P. and Nestmann, F. 2011. Hydrological Assessment of A Karst Area in Southern Java With Respect to Climate Phenomena. Asian TransDisciplinary Karst Conference 2011, Yogyakarta-INDONESIA.

Cahyadi, A dan Agniy, R.F.2016. Analisis Breakthrough Curve Untuk Karakteristerisasi Pelorongan Di Sistem Sungai Bawah Tanah Pindul Kabupaten Gunungkidul. Prosiding Pertemuan Ilmiah Tahunan Ke-1 Perhimpunan Ahli Airtanah Indonesia (PIT-PAAI). Bandung, $16-17$ November 2016 Halaman 375 - 385

Goldscheider, N., Meiman, J., Pronk, M., and Smart, C. 2008. Tracer tests in karst hydrogeology and speleology. International Journal of Speleology, 37(1), 27-40.

Haryono, E and Suratman. 2010. Significant Features of Gununngsewu Karst As Geopark Site. 4th International UNESCO Conference on Geopark, April 12-15, 2010, Langkawi.

Haryono, E dan Adji, T.N. 2004. Bahan Ajar Karst:: Yogyakarta : Fakultas Geografi UGM.

Haryono, E., Danardono, Mulatsih, S., Putro, S.T., and Adji, T.N. 2016. The Nature of Carbon Flux in Gunungsewu Karst, Java-Indonesia.

ACTA CARSOLOGICA 45(1), 173-185,

Käss W., 1998 - Tracing Technique in Geohydrology. Balkema, Rotterdam: $600 \mathrm{p}$.
Kusumayudha, S.B. 2009. Detecting Springs in the Coastal Area of the Gunungsewu Karst Terrain, Yogyakarta Spesial Province, Indonesia, using Fractal Geometry Analysis. The Journal of Technology and Science, Vol.2, No.4, pp : 1- 12.

Kusumayudha, S.B., 2002, Sistem Hidrogeologi Gunungsewu. Prosiding Sumberdaya Geologi Daerah Istimewa Yogyakarta dan Jawa Tengah. Ikatan Ahli Geologi Indonesia (IAGI) Pengda DIY-Jateng, pp 130 - 141.

Widyastuti, M., Haryono, E., Sudarmadji., dan Tivianto, T.A. 2011. Cop method modification for groundwater Vulnerability asseSSment from concentration of Flow aspect: Bribin cathment area case, gunungsewu Karst-Indonesia. Proceeding. Asian Trans Disciplinary Karst Conference 2011, Yogyakarta INDONESIA 78306.

Widyastuti, M., Riyanto, I.A., Naufal, M., Ramadhan, F., dan Rahmawati, N. 2018. Water Catchement Area Analysis of Guntur Karst Spring. Proceeding. The $2^{\text {nd }}$ International Conference on Environmental Resources Management in Global Region. Yogyakarta 22-23 Oktober 2018.

Widyastuti, M., Sudarmadji, Sutikno, dan Hendrayana, H. 2012. Kerentanan Airtanah terhadap Pencemaran Daerah Imbuhan Ponor di Karst Gunungsewu (studi di Daerah Aliran Sungai Bawah Tanah Bribin). J. Manusia dan Lingkungan 19(2), 129-142. 